\title{
Aortic valve replacement with Toronto SPV bioprosthesis: Optimal patient survival but suboptimal valve durability
}

Tirone E. David, MD, Christopher M. Feindel, MD, Joanne Bos, RN, Joan Ivanov, PhD, and Susan Armstrong, MSc

Earn CME credits at http:// cme.ctsnetjournals.org
From the Peter Munk Cardiac Centre at Toronto General Hospital and University of Toronto, Toronto, Ontario, Canada.

Tirone David reports consulting fees from St Jude Medical, Medtronic, and Edwards LifeSciences.

Read at the Thirty-third Annual Meeting of the Western Thoracic Surgical Association, Santa Ana Pueblo, NM, June 27-30, 2007.

Received for publication Jan 20, 2007; revisions received March 21, 2007; accepted for publication April 12, 2007.

Address for reprints: T. E. David, MD, 200 Elizabeth St. 4N457, Toronto, Ontario, Canada M5G 2C4 (E-mail: tirone.david@ uhn.on.ca).

J Thorac Cardiovasc Surg 2008;135:19-24

$0022-5223 / \$ 34.00$

Copyright (C) 2008 by The American Association for Thoracic Surgery

doi:10.1016/j.jtcvs.2007.04.068
Objective: Our objective was to examine the clinical outcomes of aortic valve replacement with the Toronto SPV bioprosthesis at 12 years.

Methods: The Toronto SPV was used for aortic valve replacement in 357 patients from July 1991 to December 2004. There were 244 men and 113 women with a mean age of $65 \pm 10$ years. Aortic stenosis was present in $79 \%$ of patients, coronary artery disease in $38 \%$, and left ventricular ejection fraction less than 0.40 in $12 \%$. Patients had an annual assessment of valve function using echocardiography. The mean duration of follow-up was $7.7 \pm 3.2$ years.

Results: There were 2 operative and 79 late deaths, of which 13 were valve related and 25 heart related. Survival at 12 years was $64 \% \pm 4 \%$ and similar to that of the general population matched for age and sex. Forty-nine patients had echocardiographic evidence of bioprosthetic dysfunction. The freedom from structural valve degeneration at 12 years was $69 \% \pm 4 \%$ for all patients, $52 \% \pm 8 \%$ for patients less than 65 years of age, and $85 \% \pm 4 \%$ for patients 65 years of age or older $(P=.002)$. Fifty patients had redo aortic valve replacement: 45 for structural valve degeneration and 5 for endocarditis. The freedom from redo aortic valve replacement at 12 years was $69 \% \pm 4 \%$. Cusp tear with consequent aortic insufficiency was the most common cause of structural valve degeneration. At the latest follow-up contact, 226 (63\%) patients were alive with the Toronto SPV valve in place, and $69 \%$ were in functional class I, $24 \%$ in class II, and $7 \%$ in class III.

Conclusions: The Toronto SPV bioprosthesis has provided optimal patient survival and symptomatic improvement but suboptimal valve durability, particularly in patients less than 65 years of age. We now use of this valve mostly in older patients who have a small aortic annulus.

$\mathrm{T}$ he Toronto SPV (T-SPV) bioprosthesis (St Jude Medical, Inc, St Paul, Minn) is a porcine aortic valve fixed with glutaraldehyde at a pressure of $1.5 \mathrm{~mm}$ $\mathrm{Hg}$ and with no anticalcification treatment. The valve is designed for implantation in the subcoronary position, and its outer surface is covered with a fine Dacron fabric. As with any stentless valve secured in the subcoronary position, the Toronto SPV bioprosthesis relies on the geometry of the recipient's aortic root for its support and function. For this reason, the function of this valve is highly dependent on the surgeon's ability to match the valve to the patient's aortic root and to implant. Once healed in the aortic root, it functions like a normal aortic valve. That is the reason that dilation of the aortic root causes aortic insufficiency (AI) after aortic valve replacement (AVR) with the Toronto SPV valve, as it does with the native aortic valve. ${ }^{1}$

We have used the Toronto SPV bioprosthesis since July 1991, when it became available under an investigational device exemption. It received approval by the Food and Drug Administration for clinical use in November 1997. This study is a review of our clinical experience with this heart valve. 

Abbreviations and Acronyms
AI $=$ aortic insufficiency
AVR = aortic valve replacement
SVD = structural valve degeneration
$\mathrm{T}-\mathrm{SPV}=$ Toronto SPV

\section{Patients and Methods}

The review ethics board of our institution approved this study. From July 1991 to December 2004, 357 patients underwent AVR with the T-SPV at Toronto General Hospital. Table 1 shows the clinical profile of these patients and Table 2 shows the operative

\section{TABLE 1. Clinical characteristics of patients}

\begin{tabular}{|c|c|}
\hline No. of patients & 357 \\
\hline Mean age $\pm S D(y)$ & $10 \pm 65$ \\
\hline Range (y) & $22-84$ \\
\hline \multicolumn{2}{|l|}{ Sex, No $(\%)$} \\
\hline Male & $244(68)$ \\
\hline Female & $113(32)$ \\
\hline \multicolumn{2}{|l|}{ Electrocardiogram, №. (\%) } \\
\hline Sinus rhythm & $32(92)$ \\
\hline Atrial fibrillation & $19(5)$ \\
\hline Heart block & $11(3)$ \\
\hline \multicolumn{2}{|l|}{ Timing of operation, No, (\%) } \\
\hline Elective & $297(83)$ \\
\hline Urgent/emergency & $60(17)$ \\
\hline \multicolumn{2}{|l|}{ NYHA functional classification, No. (\%) } \\
\hline Class I & $20(5)$ \\
\hline Class II & $147(41)$ \\
\hline Class III & $151(42)$ \\
\hline Class IV & $39(11)$ \\
\hline Previous AVR, No. (\%) & $18(5)$ \\
\hline Previous infective endocarditis & $7(2)$ \\
\hline \multicolumn{2}{|l|}{ Associated diseases, №. (\%) } \\
\hline Diabetes mellitus & $46(14)$ \\
\hline Peripheral vascular disease & $16(4)$ \\
\hline Hypertension & $135(38)$ \\
\hline Hyperlipidemia & $130(36)$ \\
\hline Severe COPD $\left(\mathrm{FEV}_{1} \leqslant 1.0\right)$ & $11(3)$ \\
\hline Renal failure & $5(1)$ \\
\hline \multicolumn{2}{|l|}{ LVEF, No. $(\%)$} \\
\hline$\geq 60 \%$ & $175(49)$ \\
\hline $40 \%-59 \%$ & $139(39)$ \\
\hline $20 \%-39 \%$ & $39(11)$ \\
\hline$<20 \%$ & $4(1)$ \\
\hline Coronary artery disease, No. (\%) & $136(38)$ \\
\hline \multicolumn{2}{|l|}{ Aortic valve lesion, No. (\%) } \\
\hline Aortic stenosis & $281(79)$ \\
\hline Al & $33(8)$ \\
\hline Mixed & $43(12)$ \\
\hline Ascending aortic aneurysm, No. (\%) & $11(3)$ \\
\hline
\end{tabular}

NYHA, New York Heart Association; AVR, aortic valve replacement; COPD, chronic obstructive pulmonary disease; $F E V_{1}$, forced expiratory volume in 1 second; $L V E F$, left ventricular ejection fraction; $A l$, aortic insufficiency.

\section{TABLE 2. Operative data}

\begin{tabular}{lc}
\hline Aortic valve disease, No. (\%) & \\
Degenerative calcification of tricuspid valve & $165(46)$ \\
Bicuspid aortic valve & $125(35)$ \\
Rheumatic & $18(5)$ \\
Prosthetic valve dysfunction & $18(5)$ \\
Annuloaortic ectasia & $6(2)$ \\
Miscellaneous & $25(7)$ \\
Aortic valve bioprosthetic size, No. (\%) & \\
$21 \mathrm{~mm}$ & $11(3)$ \\
$23 \mathrm{~mm}$ & $45(13)$ \\
$25 \mathrm{~mm}$ & $87(24)$ \\
27 mm & $130(36)$ \\
$29 \mathrm{~mm}$ & $82(23)$ \\
Associated procedures, No. (\%) & $136(32)$ \\
Coronary artery bypass & $11(3)$ \\
Replacement of ascending aorta & $4(1)$ \\
Mitral valve repair & $89 \pm 25$ \\
Aortic crossclamp time, min (mean \pm SD) & $109 \pm 30$ \\
CPB, min (mean \pm SD) &
\end{tabular}

$S D$, Standard deviation; $C P B$, cardiopulmonary bypass.

data. The first 174 patients were operated during the investigational device exemption trial and had annual visits to our clinics for an interview, physical examination and echocardiography to comply with the Food and Drug Administration guidelines. The referring cardiologists followed up the remaining 183 patients and echocardiography was performed in other institutions. Our research personnel contacted these 183 patients annually by telephone and collected the echocardiographic reports. The follow-up ranged from 0 to 15 years, mean of $7.7 \pm 3.2$ years, for a total of 2735 patient-years. It was $100 \%$ complete.

\section{Statistical Analysis}

All data analyses were performed with SAS 8.1 software (SAS Institute, Inc, Cary, NC). Descriptive statistics are reported as the mean \pm standard deviation for continuous variables and as frequencies and percentages for categorical variables, unless otherwise noted. Estimates for long-term survival or freedom from morbid events were made by the Kaplan-Meier method.

Age- and gender-matched Ontario survival estimates were obtained from the Life Table Template V1.2, a downloadable Excel spreadsheet available from the Association of Public Health Epidemiologists in Ontario (www.apheo.ca). This spreadsheet contains age- and gender-specific conditional probabilities of surviving a 5-year age interval. These conditional probabilities were calculated for a population similar to Canadian 1990. A more detailed description of the methods can be found in an article by Manuel, Goel, and Williams. ${ }^{2}$ The survival line depicted in Figure 1 represents the averaged conditional probabilities of survival of our age- and gender-matched patient sample.

All preoperative variables were entered into Cox regression analyses to determine the independent, multivariable predictors of late mortality and valve failure. Criterion for retention of variables in the model was set at a $P$ value of .05 . 


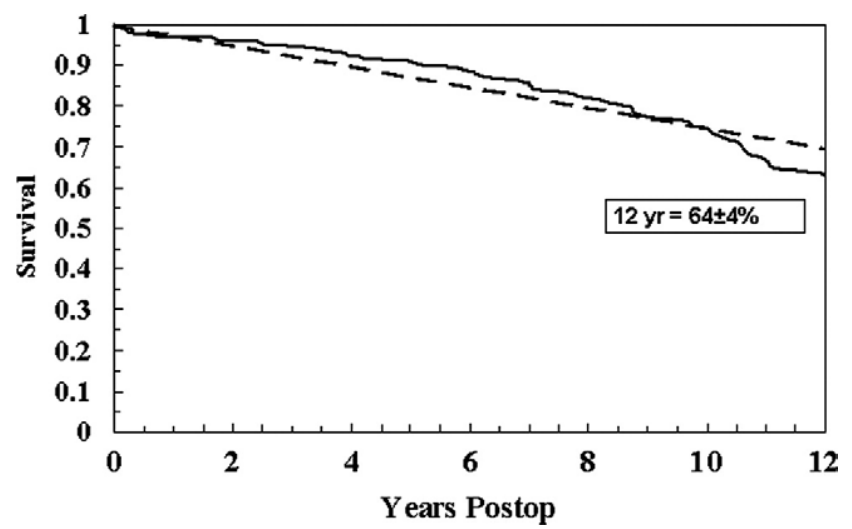

Figure 1. Survival after AVR with Toronto SPV bioprosthesis (solid line) compared with the general population of Ontario matched for age and sex (dotted line). AVR, Aortic valve replacement.

\section{Results}

\section{Patient Survival}

There were 2 operative and 79 late deaths: 13 valve related, 25 heart related, and 43 resulting from other causes. Patient survival at 12 years was $64 \% \pm 4 \%$ and only slightly lower than that of the general population of Ontario matched for age and gender, as seen in Figure 1. The only independent cardiac variable predictive of late death was left ventricular ejection fraction less than $40 \%$ (risk ratio 2.3 , 95\% confidence interval 1.3-4.4).

\section{Prosthetic Valve Endocarditis}

Twelve patients had prosthetic valve endocarditis, 3 during the first postoperative year and 8 from 1 to 11 years postoperatively. Seven patients were treated with antibiotics alone, and 3 died during or after treatment. Five patients were reoperated on during the active phase of endocarditis and 1 died. The freedom from prosthetic valve endocarditis at $1,5,10$, and 12 years was $99 \% \pm 0.4 \%, 98 \% \pm 0.7 \%$, $96 \% \pm 1 \%$, and $94 \% \pm 2 \%$, respectively.

\section{Thromboembolic Events}

Thirty-five patients had thromboembolic events: 21 stroke and 14 transient ischemic attacks. Among those who had stroke, 2 died, 13 were left with residual neurologic deficit, and 6 recovered completely. The freedom from thromboembolism at 1, 5, 10, and 12 years was $99 \% \pm 0.5 \%$, $93 \% \pm 1 \%, 88 \% \pm 2 \%$, and $83 \% \pm 3 \%$, respectively.

\section{Anticoagulation-related Hemorrhage}

Twenty-one patients were discharged from the hospital on a regimen of warfarin sodium (Coumadin) because of atrial fibrillation. At the time of the last follow-up contact, 19 patients were receiving warfarin because of either atrial

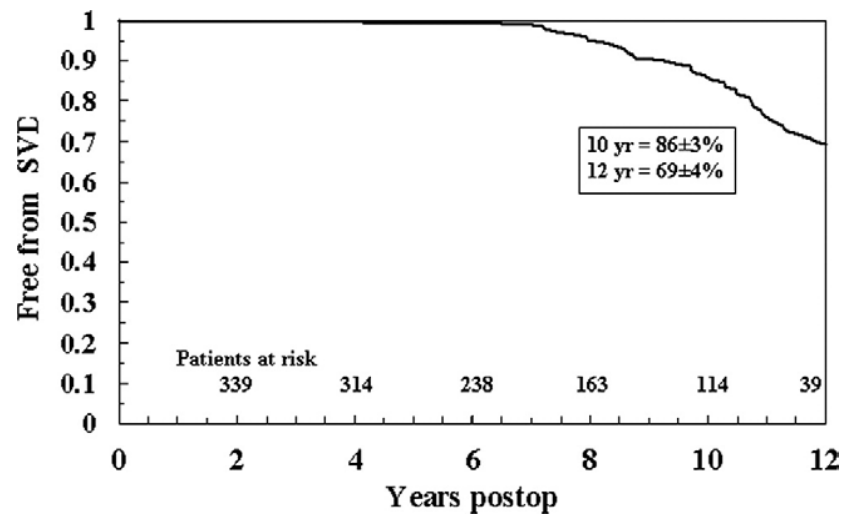

Figure 2. Freedom from structural valve degeneration (SVD).

fibrillation or a previous stroke. Only 1 patient had a major hemorrhagic complication, gastrointestinal bleeding, and died.

\section{Structural Valve Degeneration}

Forty-nine patients had echocardiographic evidence of structural valve degeneration (SVD). Severe AI was present in all but 2 patients who had aortic stenosis. Forty-five patients with SVD were reoperated on and 4 were not because of comorbid conditions. Among the 45 patients reoperated on because of SVD, cusps tears were present in 40 patients and gross calcification in 23. Two patients were reoperated on because of aortic stenosis owing to valve calcification and pannus in the inflow of the valve. Three patients had intact valves with severe AI owing to dilation of the aortic root. In 25 of 49 patients with SVD, the diameter of the sinotubular junction was $20 \%$ or larger than the diameter of the valve implanted. There were 2 operative deaths among 45 patients who had redo AVR for SVD. Four patients with SVD who were not reoperated on died of valve-related causes. The freedom from SVD at 12 years was $69 \% \pm 4 \%$ for all patients (Figure 2); for patients younger than 65 years of age it was $52 \% \pm 8 \%$, and for patients aged 65 years or older it was $85 \% \pm 4 \%(P=$ $.001)$. Cox regression analysis revealed increased age by 5 -year increments reduced the risk of SVD (risk ratio 0.73 , $95 \%$ confidence interval $0.6-0.9$ ). The actual freedom from SVD at 12 years was $76 \% \pm 3 \%$ for all patients, $60 \% \pm 7 \%$ for patients younger than 65 years of age, and $88 \% \pm 4 \%$ for patients 65 years of age and older $(P=.001)$.

\section{Reoperations}

Fifty patients had redo aortic valve surgery: 45 for SVD and 5 for prosthetic aortic valve endocarditis. There were 3 operative deaths among 50 patients undergoing reoperation. The freedom from reoperation at 12 years was $69 \% \pm 4 \%$ (Figure 3). 


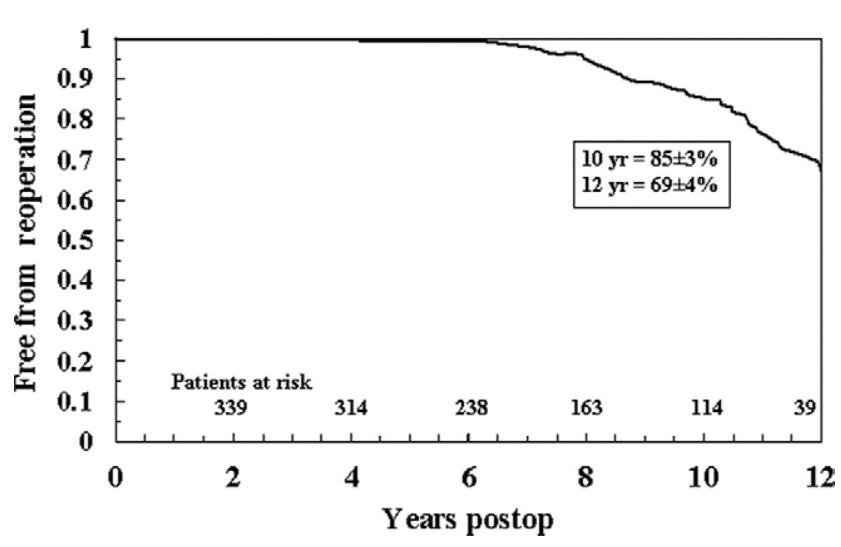

Figure 3. Freedom from reoperation.

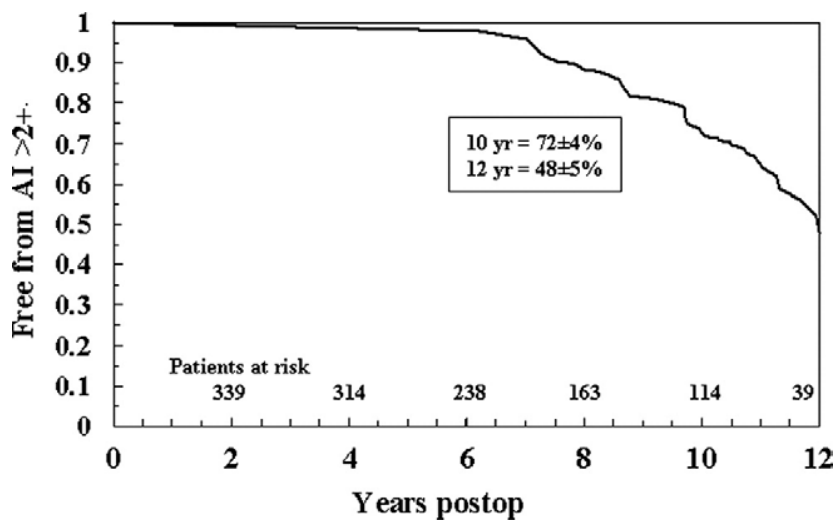

Figure 4. Freedom from moderate or severe aortic insufficiency (AI).

results among these trials was due to technical problems related to implantation of the stentless valves in the subcoronary position. In our experience, stentless valves have better hemodynamics than stented valves. ${ }^{14}$ Moreover, if the technique of aortic root replacement is used, even better hemodynamics are obtained, and this operative approach can be used as an alternative to patch enlargement of the aortic root to avoid patientprosthesis mismatch. ${ }^{15}$ Implantation of a stentless valve in the subcoronary position such as the T-SPV is complicated because the function of the donor cusps is dependent on the recipient's aortic root. Thus, matching the size of the stentless valve to the recipient aortic root and securing it in the subannular position has a profound effect on its hemodynamic performance. For instance, in one of the randomized trials, the T-SPV was compared with the Carpentier-Edwards Perimount valve (Edwards LifeSciences, Irvine, Calif), and the investigators found no difference in the hemodynamic parameters or left ventricular mass regression at 1 year postoperatively. ${ }^{9}$ However, in that study, the reported mean effective orifice areas for the T-SPV were approximately $20 \%$ smaller than those reported by others, ${ }^{4,5}$ whereas the effective orifice areas for the Carpentier-Edwards Perimount valve were approximately $20 \%$ larger than those reported by others. ${ }^{16,17}$ Pibarot and colleagues ${ }^{18}$ have demonstrated that gradients at rest and during exercise are substantially lower with stentless valves than with stented ones. Other investigators have shown that gradients during exercise increase less among patients with stentless valves than among similar patients having undergone implantation of mechanical aortic valves. ${ }^{19,20}$ Lower gradients at rest and a smaller increase in gradients during exercise suggest that the prevalence of patient-prosthesis mismatch should be uncommon after implantation of a T-SPV valve. Indeed, not a single patient in our study had patient-prosthesis mismatch at 1 year after surgery as defined as an effective aortic valve area of less than $0.85 \mathrm{~cm}^{2} / \mathrm{m}^{2}$. 
The hemodynamic advantages of stentless valves should reduce the patients' operative mortality, particularly in those with impaired left ventricular function in whom patient-prosthesis mismatch has an incremental effect on operative risk. ${ }^{21}$ Superior hemodynamic performance may also reduce late mortality, mediated by better left ventricular remodeling and performance. The survival of patients in this series of T-SVP was $64 \% \pm 4 \%$ at 12 years. The survival was identical to that of the general population of Ontario matched for age and gender up to 10 years and then declined slightly, as shown in Figure 1. This drop in survival after the first decade is possibly due to increased risk of SVD, reoperation, and other valve-related events. The survival of patients with T-SPV bioprostheses during the first decade is higher than that of patients with stented bioprosthetic valves of similar age and comorbid conditions in our institution. ${ }^{22}$ Obviously, since the conventional wisdom has been that the type of valve has no effect on patient survival, only a large controlled randomized clinical trial on stentless versus stented valves would settle the contention that stentless valves confer a survival benefit.

Although patient survival may be higher with T-SPV than that with stented valves, the reoperation rate for SVD is higher than with stented valves. ${ }^{22}$ Currently available bioprosthetic aortic valves such as the Hancock II (Medtronic, Minneapolis, Minn) appear to be associated with lower rates of SVD and reoperation. ${ }^{22}$ In our hospital, the freedom from SVD at 12 years was approximately $85 \%$ for the Hancock II and 69\% for the T-SPV in a patient population of similar age and clinical profile. Even more worrisome is the fact that at 12 years only $48 \%$ of patients with T-SPV were free from moderate or severe AI. This high rate of SVD with the T-SPV is no doubt related to increased mechanical stress on the cusps of the valve because of our inability to perfectly match the porcine cusps to the recipient's aortic root during implantation and also because of late dilation of the sinotubular junction. . $^{1,23,24}$ Actually, in one half of all patients who had severe AI, the diameter of the sinotubular junction had increased by $20 \%$ or more than the diameter of the valve implanted, suggesting that dilation of the sinotubular junction was a common cause of AI in this series. In a previous study on this topic, we $^{1}$ proposed to stabilize the sinotubular junction with a strip of Dacron fabric after implantation of the T-SPV. The effect of that maneuver will not be known for several more years because of inadequate length of follow-up.

In this study, we defined SVD as recommended in the guidelines to report outcomes on heart valve surgery. Of 49 patients with echocardiographic evidence of severe valve dysfunction, 47 had AI and 2 had stenosis, but at surgery, 3 patients with severe AI had valves without SVD, and the valves were incompetent because of dilation of the sinotubular junction. Further complicating the issue of SVD in patients with stentless valves is moderate and mild AI. If there is no echocardiographic evidence of cusp calcification, these degrees of valve dysfunction are not included in SVD. This issue should be included in future guidelines on reporting outcomes on stentless valves.

Reoperations in patients who had AVR with the T-SPV valve are more complicated than those with stented valves. Although there were only 3 operative deaths among 50 reoperations in this series, more than one half of the patients required complex reconstruction of the aortic root because the aortic sinuses and/or annulus and coronary artery orifices were damaged during removal of the valve.

In summary, AVR with T-SPV results in optimal patient survival, hemodynamic features, and symptomatic improvement in this series but suboptimal valve durability, particularly in patients less than 65 years of age. Reoperation for late valve failure is complex and often necessitates aortic root replacement and patch repair of the coronary artery orifices. For these reasons, we now use this valve mostly in older patients who have a small aortic annulus and whom we do not expect to outlive the valve.

\section{References}

1. David TE, Ivanov J, Eriksson M, Bos J, Feindel CM, Rakowski H. Dilation of the sinotubular junction causes aortic insufficiency after aortic valve replacement with the Toronto SPV bioprosthesis. J Thorac Cardiovasc Surg. 2001;122:929-34.

2. Manuel D, Goel V, Williams J. The derivation of life expectancy at the local level. Chronic Dis Can. 1998;19:52-6.

3. David TE, Pollick C, Bos J. Aortic valve replacement with stentless porcine aortic bioprosthesis. J Thorac Cardiovasc Surg. 1990;99: 113-8.

4. Jin XY, Gibson DG, Yacoub MH, Pepper JR. Perioperative assessment of aortic homograft, Toronto stentless valve, and stented valve in the aortic position. Ann Thorac Surg. 1995;60:S395-401.

5. Walther T, Falk V, Langebartels G, Krüger M, Bernhardt U, Diegeler A, et al. Prospectively randomized evaluation of stentless versus conventional biologic aortic valves: impact on early regression of left ventricular hypertrophy. Circulation. 1999;100 (19 Suppl):II6-10.

6. Williams RJ, Muir DF, Pathi V, MacArthur K, Berg GA. Randomized controlled trial of stented and stentless aortic bioprostheses: hemodynamic performance at 3 years. Semin Thorac Cardiovasc Surg. 1999; 4(suppl I):93-7.

7. Santini F, Bertolini P, Montalbano G, Vecchi B, Pessotto R, Prioli A, et al. Hancock versus stentless bioprosthesis for aortic vale replacement in patients older than 75 years. Ann Thorac Surg. 1998;66(6 suppl):S99-103.

8. Maselli D, Pizio R, Bruno LP, Di Bella I, De Gasperis C. Left ventricular mass reductions after aortic valve replacment: homografts, stentless and stented valves. Ann Thorac Surg. 1999;67:966-71.

9. Cohen G, Christakis GT, Joyner CD, Morgan CD, Tamariz M, Hanayama N, et al. Are stentless valves hemodynamically superior to stented valves? A prospective randomized trial. $>$ Ann Thorac Surg. 2002;73:767-78.

10. Doss M, Martens S, Wood JP, Aybek T, Kleine P, Wimmer Greinecker $\mathrm{G}$, et al. Performance of stentless versus stented aortic valve bioprostheses in the elderly patient: a prospective randomized trial. Eur J Cardiothorac Surg. 2003;23:299-304.

11. Totaro P, Degno N, Zaidi A, Youhana A, Argano V. CarpentierEdwards PERIMOUNT Magna bioprosthesis: a stented valve with stentless performance? J Thorac Cardiovasc Surg. 2005;130:1668-74. 
12. Perez de Arenaza D, Lees B, Flather M, Nugara F, Husebye T, Jasinski $\mathrm{M}$, et al. Randomized comparison of stentless versus stented valves for aortic stenosis: effects on left ventricular mass. Circulation. 2005;112: 2696-702.

13. Ali A, Halstead JC, Cafferty F, Sharples L, Rose F, Coulden R, et al. Are stentless valves superior to modern stented valves? A prospective randomized trial. Circulation. 2006;114(1 suppl):I535-40.

14. Borger MA, Carson SM, Ivanov J, Rao V, Scully HE, Feindel CM, et al. Stentless aortic valves are hemodynamically superior to stented valves during mid-term follow-up: a large retrospective study. Ann Thorac Surg. 2005;80:2180-5.

15. Castro LJ, Arcidi JM Jr, Fisher AL, Gaudiani VA. Routine enlargement of the small aortic root: a preventive strategy to minimize mismatch. Ann Thorac Surg. 2002;74:31-6.

16. Aupart MR, Sirinelli AL, Diemont FF, Meurisse YA, Dreyfus XB, Marchand MA. The last generation of pericardial valves in the aortic position: ten-year follow-up in 589 patients. Ann Thorac Surg. 1996; 61:615-20.

17. Dellgren G, David TE, Raanani E, Armstrong S, Ivanov J, Rakowski H. Late hemodynamic and clinical outcomes of aortic valve replacement with the Carpentier-Edwards Perimount pericardial bioprosthesis. J Thorac Cardiovasc Surg. 2002;124:146-54.

18. Pibarot P, Dumesnil JG, Jobin J, Cartier P, Honos G, Durand LG. Hemodynamic and physical performance during maximal exercise in patients with an aortic bioprosthetic valve: comparison of stentless versus stented bioprosthesis. J Am Coll Cardiol. 1999;34:1609-17.

19. Silberman S, Shaheen J, Merin O, Fink D, Shapira N, Liviatan-Strauss $\mathrm{N}$, et al. Exercise hemodynamics of aortic prostheses: comparison between stentless bioprostheses and mechanical valves. Ann Thorac Surg. 2001;72:1217-21.

20. Morsy S, Zahran M, Usama M, Elkhashab K, Abdel-Aziz I. Hemodynamic performance of stentless porcine bioprosthesis and mechanical bileaflet prosthesis using dobutamine stress echocardiography. Semin Thorac Cardiovasc Surg. 2001;13 (4 Suppl 1):129-35.

21. Blais C, Dumesnil JG, Baillot R, Simard S, Doyle D, Pibarot P. et al. Impact of valve prosthesis-patient mismatch on short-term mortality after aortic valve replacement. Circulation. 2003;108:983-8.

22. David TE, Ivanov J, Armstrong S, Feindel CM, Cohen G. Late results of heart valve replacement with the Hancock II bioprosthesis. J Thorac Cardiovasc Surg. 2001:121:268-77.

23. Thubrikar MJ, Gong GG, Konstantinov IE, Selim GA, Fowler BL, Robicsekk F. Influence of sizing and subcoronary implantation technique on the function of porcine aortic homografts. J Med Eng Technol. 200024:173-80.

24. Van Nooten G, Ozaki S, Herijgers P, van Belleghem Y, Flameng W. Deformation of the stentless porcine valve scaffold enhances accelerated leaflet fibrosis and calcification in juvenile sheep. Sem Thorac Cardiovasc Surg. 1999;11(suppl 1):163-70.

\section{Discussion}

Dr Arvind Koshal (Edmonton, Alberta, Canada). Thank you very much, Dr David, for an excellent presentation. This is an excellent example to all of us of how you took a product from the initial development stage, brought it into the market, and are now providing us with $100 \%$ follow-up on these 357 patients. You should be congratulated for doing that and giving us a lot of information.

It is interesting that the survival has been good despite a durability issue that we have seen with tissue valves in the past. The difference, though, in using stented valves with poor durability was that at the time of reoperation, the reoperation was not that technically complicated. What were the technical problems on reoperation in these patients who have a more complex way of insertion and also where coronary ostia and sinuses are involved? What kind of valve or conduit do you use at that stage?
Dr David. The experience is largely personal. We have operated on 50 patients, and 28 required aortic root replacement because in attempting to remove the valve we damaged the aortic sinuses and/or aortic arch annulus. The operative mortality for elective reoperation for failed stentless valves is twice as high as for bioprostheses.

Dr Koshal. What kind of valve did you use at the second operation?

Dr David. Surprisingly, most patients wanted a bioprosthesis again.

Dr Koshal. The other interesting thing in your series is that you have a significant percentage of bicuspid aortic valves. As you know, with bicuspid valves the aorta is more prone to degenerative changes. Did you find a difference in the durability in the bicuspid versus the tricuspid valves that were replaced?

Dr David. That is an important question. Patients with bicuspid aortic valves eventually had aortic dilation, and because this valve function is dependent on the aortic root, if the aorta dilates the valve becomes incompetent. This was the case, unfortunately, but bicuspid aortic valve was not a predictor of late failure. Dilatation of the aorta was. Unfortunately, the literature suggests that the aorta dilates as we age. In the age group of 50 to 80 years, if the aorta increases from 25 to $30 \mathrm{~mm}$ in diameter to $35 \mathrm{~mm}$ or so, this valve is rendered incompetent. I learned this only in 1998 and I started banding it, but we do not have long enough follow-up on those patients. Clearly, dilatation of the aorta was the most common mode of failure in these patients.

Dr Koshal. Finally, what are you going to do with this valve now? How many of these do you use in your practice and what have you changed to?

Dr David. I continue using it but I do not use it in younger patients anymore. The enthusiasm was so great 18 years ago when it was first developed. We thought it was going to take over the use of homografts because it is relatively easy to implant and I thought it was going to be more durable. We limit it to older patients, over 65 or 70 years. In those, failure is uncommon. Hemodynamically, it is an outstanding valve.

Dr John Brown (Indianapolis, Ind). Do you have any comparison of the Toronto valve with the other stentless valves on the market to see whether they are showing the same problems that the Toronto valve has?

Dr David. We do, Dr Brown. We have followed up most patients who had valve surgery with biological and bioprosthetic valves. Compared with the Hancock II, this valve is not as durable, not by much though. At 10 years there is a $10 \%$ difference and at 12 years a $12 \%$ difference for all comers. However, the survival at 12 years is $20 \%$ better for the stentless valve. I am not saying that if I need an AVR, I am going to have a stentless valve because I am likely to live longer than the durability of this valve. The beneficial effect of better hemodynamics likely is not apparent in the first year or two. It might take a decade or more to become apparent. I firmly believe that if a patient comes for AVR, the surgeon should resolve the hemodynamic burden that the native aortic valve disease caused. This valve is very close to it in elderly patients, and that is why I continue using Ross in younger patients. I think it is an outstanding operation in properly selected patients. It restores the outflow tract to normality. 